\title{
Markers of Local Inflammation and Bone Resorption in the Acute Diabetic Charcot Foot
}

\author{
Rasmus Bo Jansen (D), 1,2 Tomas Møller Christensen, ${ }^{2}$ Jens Bülow, ${ }^{3}$ Lene Rørdam, ${ }^{3}$ \\ Niklas Rye Jørgensen, ${ }^{4,5}$ and Ole Lander Svendsen ${ }^{1,2}$ \\ ${ }^{1}$ Copenhagen Diabetes Foot Center (CODIF), Bispebjerg Hospital, University of Copenhagen, 2400 Copenhagen NV, Denmark \\ ${ }^{2}$ Department of Endocrinology, Bispebjerg Hospital, University of Copenhagen, 2400 Copenhagen NV, Denmark \\ ${ }^{3}$ Department of Clinical Physiology and Nuclear Medicine, Bispebjerg Hospital, University of Copenhagen, \\ 2400 Copenhagen NV, Denmark \\ ${ }^{4}$ Department of Clinical Biochemistry, Rigshospitalet, University of Copenhagen, 2600 Glostrup, Denmark \\ ${ }^{5}$ Odense Patient data Explorative Network (OPEN), Odense University Hospital/Institute of Clinical Research, University of \\ Southern Denmark, Odense, Denmark
}

Correspondence should be addressed to Rasmus Bo Jansen; rasmus.bo.jansen@regionh.dk

Received 24 January 2018; Revised 5 June 2018; Accepted 25 June 2018; Published 2 August 2018

Academic Editor: Mark Yorek

Copyright (c) 2018 Rasmus Bo Jansen et al. This is an open access article distributed under the Creative Commons Attribution License, which permits unrestricted use, distribution, and reproduction in any medium, provided the original work is properly cited.

\begin{abstract}
Objective. Due to the localized nature of Charcot foot, systemically altered levels of inflammation markers can be difficult to measure. The aim of this study was to investigate whether it is possible to detect an arteriovenous (A-V) flux in any locally produced inflammatory biomarkers from an acute Charcot foot by comparing local and systemic measurements. Methods. We included patients with acute diabetic Charcot foot. Blood was sampled from the vena saphena magna on the distal part of the crus bilaterally as well as from the arteria radialis. To minimize the A-V shunting effect, the feet were externally cooled with ice water prior to resampling. Results. Both before and after cooling, the A-V flux of interleukin-6 (IL-6) between the Charcot feet and the arterial level was significantly higher than the flux between the healthy feet and the arterial level $\left(\Delta\right.$ value $_{\text {before: }} 7.25$ versus $0.41 \mathrm{pg} / \mathrm{mL}$, resp., $p=0.008 ; \Delta$ value $_{\text {after }}: 10.04$ versus $1.68 \mathrm{pg} / \mathrm{mL}$, resp., $p=0.032$ ). There were no differences in the fluxes for other markers of inflammation. Conclusion. We have found an increased A-V flux of IL-6 in the acute diabetic Charcot foot compared to the healthy foot in the same patients.
\end{abstract}

\section{Introduction}

Charcot osteoarthropathy is a rare disorder manifesting with aseptic inflammation and hyperemia in and around loadbearing bones and tissues. The process is normally unilateral and leads to progressive, uncontrolled resorption and degeneration of bone mass, resulting in spontaneous fatigue bone fractures [1-4]. While different locations have been described, the most common is in the feet (Charcot foot (CF)) $[5,6]$, where the process can cause deformity, ulcerations, and amputations. The Charcot inflammation can be located at different sites in the affected foot, most prominently in the midfoot $[2,7]$.
The precise pathological mechanisms underlying Charcot foot are still not fully understood. However, it is dependent on relatively unimpaired lower limb blood flow and established peripheral neuropathy [8-11]. It can be triggered by a number of diseases, although today most cases occur in individuals with diabetes mellitus $[1,2,12]$.

Recent evidence suggests that the initial inflammation is provoked by repeated local microtrauma and dysregulated bone resorption [13-16], which in turn initiates the inflammatory process.

Several studies have reported changes in biomarkers of bone resorption and inflammation in individuals with 
Charcot foot [17-24], and it seems that the inflammation leads to microstructural changes in the affected bones $[25,26]$.

Related to this, studies have explored the possible relationship between interleukin levels and acute Charcot foot $[17,27-29]$ and found increased levels of interleukin-1 receptor antagonist (IL-1RA), tumor necrosis factor $\alpha$ (TNF- $\alpha$ ), interleukin-6 (IL-6), and interleukin-17 subtypes A, E, and $\mathrm{F}$ (IL-17A/E/F), as well as decreased levels of interleukin-1 $\beta$ (IL-1 $\beta$ ) and interleukin-8 (IL-8).

In addition, many individuals with Charcot foot also seem to have a degree of vascular calcification and inflammation $[30,31]$. This is of particular interest due to the connection between vascular calcification, neuropathy, and the nuclear factor $-\kappa \mathrm{B}(\mathrm{NF}-\kappa \mathrm{B})$ system, as described by Petrova and Shanahan [32]. A possible way to assess this could be through the system of advanced glycation end products (AGEs) and their soluble receptors (sRAGE) [33-35].

However, the biomarkers in question might only be produced locally around the inflamed bones in the foot, which means that the signal on a systemic level can be difficult to register. Furthermore, a general systemic release of these biomarkers might happen in response to a number of inflammatory processes unrelated to the Charcot foot.

Therefore, it is plausible that a stronger and more specific signal from an acute Charcot foot might be achieved by measuring the flux of a specific marker between the local venous concentration in the foot and the arterial concentration. Local sampling from the dorsal venous arch of the foot in acute Charcot feet has previously been done by Gough et al. and Pearson et al. [21, 23], although neither measured all the markers discussed here. To our knowledge, local fluxes of inflammatory biomarkers across an acute Charcot foot have not been measured previously.

The aim of this study was to investigate whether it is possible to detect a flux in any locally produced biomarkers from an acute Charcot foot by measuring the arteriovenous (A-V) difference.

\section{Materials and Methods}

2.1. Participants. We included participants with acute Charcot foot, recruited at the Copenhagen Wound Healing Center at Bispebjerg Hospital, Denmark, and at the Steno Diabetes Center, Gentofte, Denmark. The participants were referred by specialists after thorough physical examination, full blood panel, X-ray, bone scintigraphy, and/or MRI. All participants were examined as close as possible to the reported outbreak of the acute Charcot symptom ( $<3$ months).

Exclusion criteria included no diabetes mellitus, temperature difference $<2^{\circ} \mathrm{C}$ between the feet, duration $>3$ months, foot ulcers, prior foot surgery, new objective foot deformities, bilateral Charcot foot, infection in the foot, antiosteoporotic medication, arterial insufficiency, or foot or toe amputation on either side.

To confirm that the Charcot foot still had a high activity on the day of examination as assessed by a locally elevated blood flow, this was measured in the feet with venous occlusion plethysmography [36]. Foot temperature and foot somatosensoric neuropathy as assessed by biothesiometry were measured on the study day as well.

The study was approved by the Regional Ethical Committee for Copenhagen.

2.2. Arteriovenous Flux. To measure the fluxes in biomarker production in the acute Charcot foot, blood was sampled from the vena saphena magna on the distal part of the crus above the ankle. This was done on both the affected (Charcot) side and the healthy side. Arterial blood was sampled from the a. radialis (or from the a. brachialis if the a. radialis was inaccessible).

The venous drainage of the foot happens primarily through the veins saphena magna and parva, while the deep veins only play a minor role. The saphena veins connect through the dorsal venous arch on the dorsal side of the foot. The dorsal venous arch collects blood from both superficial and deep veins in the foot, as well as from the networks rete venosus plantare and rete venosus dorsale pedis. The superficial and deep veins of the foot are linked by communicating perforant veins. The few valves present in these perforants are turned so that blood can only run from the deep to the superficial veins, thus helping with thermoregulation and pressure absorption. This means that parts of the drainage of the deep foot happen through the superficial veins, which can thus be sampled from a superficial vein on the lower leg [37-39].

A portion of the blood flow in the feet bypasses normal microcirculatory exchange by shunting directly through $\mathrm{A}-\mathrm{V}$ anastomoses. This is in part a thermoregulatory effect and is thus more prevalent at higher skin temperatures [40]. As the shunted blood will not be exposed to any biomarkers produced in the deep foot tissue, this $\mathrm{A}-\mathrm{V}$ shunting in effect dilutes the signal of any inflammatory biomarkers in a mixed venous sample. To minimize this shunting effect in our setup, we cooled down the feet externally with cold water prior to the final sampling $\left(t_{\text {ice }}\right)$.

2.3. Experimental Setup. All three sites were sampled simultaneously $\left(t_{\text {start }}\right)$ (Figure 1$)$. Fluxes between the arterial and venous concentrations were calculated as vein - artery to get a positive gradient if the Charcot foot produced the biomarker in question. After sampling, both feet were cooled down for approximately 10 minutes in an icy water bath, while foot temperature was measured. The three sites were then sampled again while the participants kept their feet in the water $\left(t_{\text {ice }}\right)$.

In the following, venous samples from the acute Charcot foot are denoted as $\mathrm{CF}(\mathrm{v})$ and venous samples from the nonCharcot foot are denoted as non-CF(v).

The blood samples were centrifuged at $4^{\circ} \mathrm{C}$ and stored at $-80^{\circ} \mathrm{C}$. All samples were analyzed together at the end of the study.

2.4. Biomarkers. To estimate the existing interleukin profile and the highest relative concentrations, $t_{\text {start }}$ samples were analyzed on a Bio-Plex System multiplex immunoassay screening panel (Bio-Rad Laboratories Inc., 4000 Alfred Nobel Drive, Hercules, California 94547, USA). The panel 


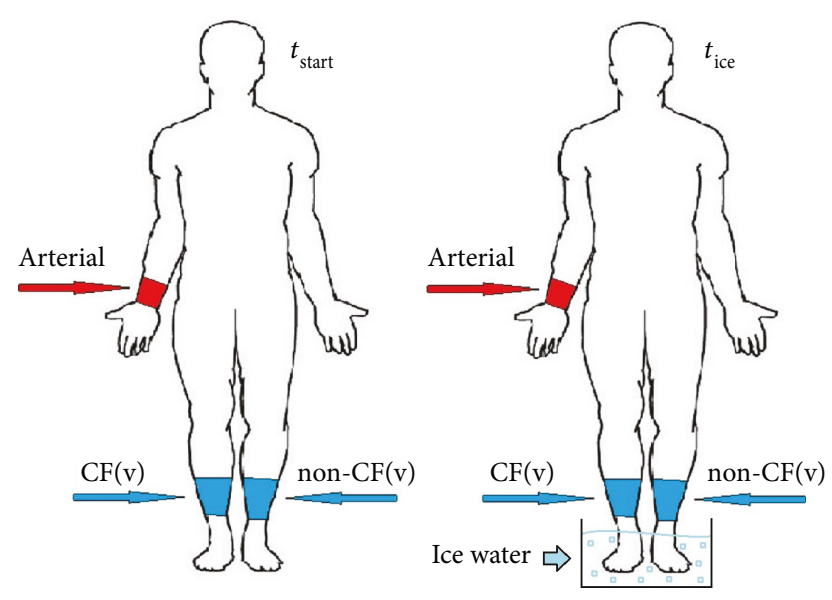

FIGURE 1: Sites of arterial (red) or venous (blue) blood samples before $\left(t_{\text {start }}\right)$ and after $\left(t_{\text {ice }}\right)$ external cooling of the feet. Arterial samples were taken from the a. radialis, or from the a. brachialis if the a. radialis was inaccessible. Venous samples were taken from a large superficial vein at the third distal part of the crus both on the side with a Charcot foot $(\mathrm{CF}(\mathrm{v}))$ and on the side without a Charcot foot (non-CF(v)).

used screened for IL-1 $\beta$, IL-1RA, IL-6, IL-8, IL-17A, and TNF- $\alpha$, with the best signals detected for IL- 6 and IL-8.

All analyses were performed by Biolab, Department of Clinical Biochemistry, Rigshospitalet, University of Copenhagen, Denmark. Special ELISA setups were used for IL-6, IL-8, free soluble receptor activator of nuclear factor kappa- $B$ ligand (fsRANK-L), osteoprotegerin (OPG), IL-17F, sRAGE, and AGEs. The remaining samples were analyzed as part of the daily hospital sample routines. The accepted intraindividual sample CV for all assays was $20 \%$.

(i) AGEs were measured with a Human sandwich ELISA AGE kit (Nordic BioSite AB, Propellervägen 4A, 18362 Täby, Sweden) (kit serial number LS-F10641-1; range $0.78-50 \mathrm{ng} / \mathrm{mL}$ ).

(ii) IL-6 was measured with an IL-6 Quantikine HS ELISA kit (Bio-Techne Ltd., 614 McKinley Place NE, Minneapolis, MN 55413, USA) (kit serial number HS600B).

(iii) IL-8 was measured with a Human CXCL8 Quantikine kit (Bio-Techne Ltd., 614 McKinley Place NE, Minneapolis, MN 55413, USA) (kit serial number D8000C).

(iv) IL-17F was measured with a Human IL-17F Platinum ELISA kit (AH-Diagnostics A/S, Runetoften 18, DK-8210 Aarhus V, Denmark) (kit serial number BMS2037/2).

(v) Assays for fsRANK-L, osteoprotegerin, and sRAGE were performed as previously described [41].

2.5. Statistical Analysis. Data are presented as mean $\pm 1 \mathrm{SD}$ or range unless otherwise noted. An $\alpha$-level of $<0.05$ was considered significant. Normal distribution in data was tested using
Shapiro-Wilks tests. No transformations were used. $t$-tests or paired $t$-tests were used for variance analysis between groups in normally distributed data sets. For data sets not normally distributed, nonparametric tests in the form of the MannWhitney rank-sum test were used, while Wilcoxon signedrank tests were used for comparing paired samples.

Statistics and general data handling were done using IBM SPSS Statistics v. 23 by IBM Corporation, SIGMAPLOT v. 11.0.0.77 by Systat Software Inc., Microsoft Excel 2000 v. 9.0.2812 by Microsoft Corporation, and Apache OpenOffice 4.0.1 by the Apache Software Foundation.

\section{Results}

3.1. Participants. We included 5 patients with acute Charcot foot. In total, 22 patients were screened for inclusion. Of these, 7 patients were excluded due to having foot ulcers or receiving foot surgery and/or ulcer debridement before the examinations. Another $7 \mathrm{did}$ not want to participate or were unable to participate due to personal reasons, while 3 patients had had their Charcot foot for too long to be considered acute (duration $>3$ months).

The average time from the reported onset of symptoms to examination was 7.2 weeks. The Charcot feet were on average $2.6^{\circ} \mathrm{C}$ warmer than the contralateral and had a 3 times increased blood flow. All 5 patients had recently started offloading treatment with an AirCast ${ }^{\circledR}$ removable walker boot before measurements. All 5 patients were diagnosed with stage 0 Charcot foot.

Anthropometric data for the participants are listed in Table 1, along with the results for biothesiometry, venous occlusion plethysmography, and arterial samples of markers of bone health taken prior to the cooling of the feet $\left(t_{\text {start }}\right)$. There were a significant higher temperature and blood flow in the acute Charcot feet compared to the healthy feet.

3.2. Multiplex Data. For IL-1 $\beta$, IL-1RA, IL-17A, and TNF- $\alpha$, almost all measured values were below the multiplex limit of detection in all samples. This was tested with both serum and plasma. The detection limits were $1.32 \mathrm{pg} / \mathrm{mL}$ for IL-1, $29.64 \mathrm{pg} / \mathrm{mL}$ for IL-1RA, $7.99 \mathrm{pg} / \mathrm{mL}$ for IL-17A, and $12.72 \mathrm{pg} / \mathrm{mL}$ for TNF- $\alpha$. There was a single signal in one patient in IL-1RA and IL-17A (not the same patient for both markers).

The average level of IL- 6 detected was $10.6 \mathrm{pg} / \mathrm{mL}$, and for IL-8, it was $12.5 \mathrm{pg} / \mathrm{mL}$.

3.3. Measurements before Cooling. Measurements from all three sites (arterial, $\mathrm{CF}(\mathrm{v})$, and non-CF(v)) before and after cooling are listed in Table 2. At $t_{\text {start }}$, there were no differences in the levels of fsRANK-L, OPG, IL-6, IL-8, sRAGE, or AGEs-neither between arterial and $\mathrm{CF}(\mathrm{v})$ nor between $\mathrm{CF}(\mathrm{v})$ and non-CF(v) samples. The highest relative numerical difference was for IL-6 in arterial versus CF(v) levels (7.31 versus 14.56$)(p=0.109)$. It was not possible to measure IL-17F as it was below the assay detection limit of $7.8 \mathrm{pg} / \mathrm{mL}$ for all samples at $t_{\text {start }}$ and $t_{\text {ice }}$.

The venous-arterial flux of IL- 6 between the Charcot feet and the arterial level was significantly higher than the flux 
TABle 1: Anthropomorphic data for diabetes patients with acute Charcot foot (CF). Test results are from arterial sampling.

(a)

\begin{tabular}{lc}
\hline & Data listed as mean; range or $n$ \\
\hline Age (years) & $48.6 ; 26.0$ \\
Sex $(\mathrm{m} / \mathrm{f})$ & $3 / 2$ \\
Affected foot (left/right) & $1 / 4$ \\
Diabetes type (I/II) & $2 / 3$ \\
Diabetes duration (years) & $19.2 ; 31.0$ \\
HbAlc (mmol/mol) $(31-44 \mathrm{mmol} / \mathrm{mol})$ & $73 ; 53$ \\
$\mathrm{Ca}{ }^{2+}($ free, ionized) $(\mathrm{mmol} / \mathrm{L})(1.18-1.32 \mathrm{mmol} / \mathrm{L})$ & $1.24 ; 0.14$ \\
PTH $(\mathrm{pmol} / \mathrm{L})(1.6-6.9 \mathrm{pmol} / \mathrm{L})$ & $4.5 ; 4.3$ \\
CRP $(\mathrm{mg} / \mathrm{L})(<10 \mathrm{mg} / \mathrm{L})$ & $9.8 ; 15.0$ \\
$25-\mathrm{OH}-\mathrm{vitamin} \mathrm{D}(\mathrm{nmol} / \mathrm{L})(50-160 \mathrm{nmol} / \mathrm{L})$ & $36.7 ; 52.6$ \\
Alkaline phosphatase $(\mathrm{bone} s p e c i f i c)(\mu \mathrm{g} / \mathrm{L})(<20 \mu \mathrm{g} / \mathrm{L})^{\$}$ & $20.3 ; 7.3$ \\
CTX $(\mathrm{ng} / \mathrm{L})(<630 \mathrm{ng} / \mathrm{L})^{\$}$ & $240 ; 0.5$ \\
P1NP $(\mu \mathrm{g} / \mathrm{L})(22-87 \mu \mathrm{g} / \mathrm{L})^{\$}$ & $48.3 ; 53.8$ \\
Osteocalcin $(\mu \mathrm{g} / \mathrm{L})(9-42 \mu \mathrm{g} / \mathrm{L})$ & $25.3 ; 42.1$ \\
\hline
\end{tabular}

(b)

\begin{tabular}{lccc}
\hline & Charcot foot & Contralateral foot & Difference, $p$ value \\
\hline Foot temperature $(\mathrm{CF} / \mathrm{non}-\mathrm{CF})\left({ }^{\circ} \mathrm{C}\right)$ & 33.7 & 31.1 & $\Delta 2.6, p=0.004^{*}$ \\
Biothesiometry $(\mathrm{CF} / \mathrm{non}-\mathrm{CF})(\mathrm{V})$ & 42 & 39 & $\Delta 3, p=0.648$ \\
Plethysmography $(\mathrm{CF} / \mathrm{non}-\mathrm{CF})(\mathrm{mL} /(100 \mathrm{~g} \cdot \mathrm{min}))$ & 6.9 & 1.8 & $\Delta 5.1, p=0.045^{*}$ \\
\hline
\end{tabular}

${ }^{*}$ Significant at the chosen $\alpha$-level of $0.05 .{ }^{\$}$ Reference range listed for 50 y.o. male where ranges differ with age and/or sex.

TABLE 2: Levels of inflammation markers in local venous samples in the acute Charcot foot $(\mathrm{CF}(\mathrm{v}))$, the healthy foot (non-CF(v)), and arterial samples from the a. radialis. Measurements listed before $\left(t_{\text {start }}\right)$ and after $\left(t_{\text {ice }}\right)$ external cooling of both feet with ice water.

\begin{tabular}{lccc}
\hline & Sampling site & $t_{\text {start }}$ & $t_{\text {ice }}$ \\
\hline & Arterial & $0.14 \pm 0.12$ & $0.13 \pm 0.11$ \\
fsRANK-L (pmol/L) & CF(v) & $0.13 \pm 0.11$ & $0.14 \pm 0.11$ \\
& non-CF(v) & $0.13 \pm 0.11$ & $0.14 \pm 0.13$ \\
\hline \multirow{3}{*}{ OPG (pmol/L) } & Arterial & $6.5 \pm 5.4$ & $6.6 \pm 5.1$ \\
& CF(v) & $6.4 \pm 5.8$ & $7.3 \pm 5.9$ \\
& non-CF(v) & $6.3 \pm 5.5$ & $7.5 \pm 6.1$ \\
\hline \multirow{3}{*}{ IL-6 (pg/mL) } & Arterial & $7.31 \pm 6.88$ & $6.25 \pm 5.21$ \\
& CF(v) & $14.56 \pm 14.27$ & $16.29 \pm 11.45$ \\
& non-CF(v) & $7.71 \pm 7.07$ & $7.93 \pm 5.70$ \\
\hline \multirow{2}{*}{ IL-8 (pg/mL) } & Arterial & $15.6 \pm 7.9$ & $13.1 \pm 6.3$ \\
& CF(v) & $13.4 \pm 4.4$ & $12.1 \pm 6.3$ \\
& non-CF(v) & $14.5 \pm 9.6$ & $11.5 \pm 4.7$ \\
\hline \multirow{2}{*}{ sRAGE (ng/L) } & Arterial & $845 \pm 266$ & $860 \pm 247$ \\
& CF(v) & $833 \pm 292$ & $878 \pm 298$ \\
& non-CF(v) & $827 \pm 252$ & $911 \pm 293$ \\
\hline \multirow{3}{*}{ AGEs (ng/mL) } & Arterial & $6.2 \pm 7.7$ & $5.4 \pm 7.4$ \\
& CF(v) & $5.7 \pm 6.8$ & $7.9 \pm 7.1$ \\
& non-CF(v) & $5.9 \pm 7.2$ & $8.4 \pm 8.4$ \\
\hline
\end{tabular}

Data listed as mean $\pm 1 \mathrm{SD}$. fsRANKL $=$ free soluble receptor activator of nuclear factor $-\kappa \mathrm{B} ; \quad \mathrm{OPG}=$ osteoprotegerin; $\quad \mathrm{IL}-6 / \mathrm{IL}-8=$ interleukin 6/interleukin 8; sRAGE = soluble receptor for advanced glycation end products; AGEs = advanced glycation end products. between the healthy feet and the arterial level ( $\Delta$ values: 7.25 versus $0.41 \mathrm{pg} / \mathrm{mL}$, resp.) $(p=0.008)$. There were no differences in fsRANK-L, OPG, IL-8, sRAGE, or AGEs.

3.4. Measurements after External Cooling. The ice bath used for cooling maintained an average temperature of $7.7^{\circ} \mathrm{C}$, and it was used for cooling for an average of $11.6 \mathrm{~min}$. The ice bath cooled the Charcot feet at an average of $11.0^{\circ} \mathrm{C}$ (from 33.7 to $22.7^{\circ} \mathrm{C}$ ), and the non-Charcot feet were cooled at an average of $12.9^{\circ} \mathrm{C}$ (from 31.1 to $18.2^{\circ} \mathrm{C}$ ). Temperatures in each foot before and after cooling are listed in Table 3.

At $t_{\text {ice }}$, there was a significantly elevated level of IL-6 ( $\Delta$ value: $10.04 \mathrm{pg} / \mathrm{mL}$ ) in the Charcot feet compared to the arterial value $(p=0.049)$ (Figure 2$)$. There was also a significantly elevated level of AGEs ( $\Delta$ value: $2.5 \mathrm{ng} / \mathrm{mL})(p=0.002)$ (Table 2). There were no differences in fsRANK-L, OPG, IL-8, or sRAGE.

The venous-arterial flux for IL- 6 at $t_{\text {ice }}$ was still significantly increased in the Charcot feet $(\mathrm{CF}(\mathrm{v})$-arterial) compared to the healthy feet (non-CF(v)-arterial) ( $\Delta$ values: 10.04 versus $1.68 \mathrm{pg} / \mathrm{mL})(p=0.032)$. There were no differences in the fluxes for fsRANK-L, OPG, IL-8, sRAGE, or AGEs.

The fsRANK-L/OPG ratio at $t_{\text {ice }}$ was 3.7 in the arterial sample, 4.0 in the $\mathrm{CF}(\mathrm{v})$ sample, and 3.8 in the non-CF(v) sample and did not differ in a one-way ANOVA on ranks ( $p=0.970)$. 
TABLE 3: Temperature measurements on the feet of each individual patient during the study day.

\begin{tabular}{lcccc}
\hline \multirow{2}{*}{ Patient number } & \multicolumn{2}{c}{ Charcot foot temperature $\left({ }^{\circ} \mathrm{C}\right)$} & \multicolumn{2}{c}{ Non-Charcot foot temperature $\left({ }^{\circ} \mathrm{C}\right)$} \\
Before cooling $\left(t_{\text {start }}\right)$ & After cooling $\left(t_{\text {ice }}\right)$ & Before cooling $\left(t_{\text {start }}\right)$ & 29.7 & 18.0 \\
\hline 1 & 32.0 & 20.0 & 31.7 & 18.6 \\
2 & 33.8 & 25.9 & 32.3 & 20.6 \\
3 & 33.7 & 20.2 & 31.0 & 17.0 \\
4 & 34.8 & 21.8 & 30.7 & 17.0 \\
5 & 34.4 & 25.7 & & \\
\hline
\end{tabular}

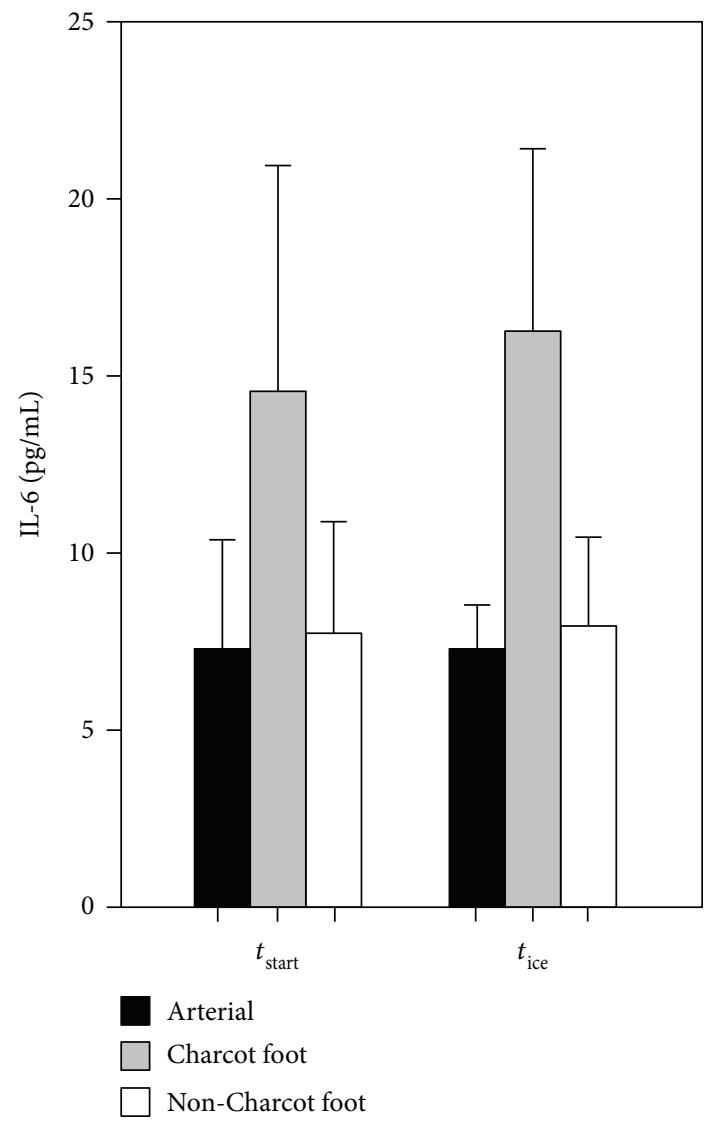

FIGURE 2: Levels of interleukin 6 (IL-6) in arterial and local venous samples in both feet $\left(\mathrm{CF}(\mathrm{v})\right.$ and non-CF(v)) before $\left(t_{\text {start }}\right)$ and after $\left(t_{\text {ice }}\right)$ external cooling with ice water. Bars=mean; error bars $=$ SEM.

\section{Discussion}

In this study, we have tested a novel approach to evaluating the local inflammatory activity in an acute Charcot foot by measuring the venous-arterial flux across the Charcot foot while lowering the possible dilution from $\mathrm{A}-\mathrm{V}$ shunting by externally cooling the foot.

The data show a difference in the venous-arterial flux of IL-6 both before and after external cooling. We also saw a two-fold elevated level of IL-6 in the Charcot foot compared to the arterial level after cooling, indicating a local production of IL-6. It is interesting that both IL-6 and AGEs only show a significant difference between the Charcot foot and arterial level after cooling, thus possibly indicating an effect of limiting $\mathrm{A}-\mathrm{V}$ shunting in the feet before sampling.

The results are mostly in line with what other groups have found. Divyateja et al. indicated an increased median IL-6 level in the Charcot foot [24], while both Petrova et al. [17] and Folestad et al. [29] have suggested increased levels of IL-6 systemically (although Folestad et al. did not find an initially increased level of IL-6).

Unlike Folestad et al., we have been unable to demonstrate high levels of IL-17F systemically in acute Charcot patients [27]. However, they did show an initial low level of IL-17F (corresponding to the time where we performed our sampling), and additionally, they used high-sensitivity ECL as opposed to the ELISA that we used.

A finding of locally increased levels of IL-6 is of particular interest for several reasons. As a proinflammatory cytokine, its presence supports the theory regarding the pathogenesis of acute Charcot foot as put forth by, for instance, Jeffcoate et al. [13]. Furthermore, IL-6 is involved in bone resorption through osteoclastic differentiation and activation [42-45]. Thus, the finding further supports local osteoclastic hyperactivation as a central element in the Charcot foot bone metabolism and confirms the findings of IL-6 in osteoclasts in bone samples from Charcot feet as seen by Baumhauer et al. [46]. The source of this local production of IL-6 remains unknown.

Recently, Petrova et al. reported that OPG was elevated in patients with Charcot foot without a corresponding elevation in RANK-L [17] and that osteoclasts from patients with Charcot foot can be modulated by TNF- $\alpha$ through RANK-L [47]. It is important to note however that elevated OPG levels could be associated with neuropathy in itself [48].

Ndip et al. have indicated that individuals with Charcot foot have an increased RANK-L/OPG ratio and suggest that this could play a role in medial vascular calcification [22]. We have also previously shown a higher RANK-L/OPG ratio in patients with acute Charcot foot than non-Charcot diabetic controls [41]. In the current setup, we did not find a difference in the venous-arterial flux or a locally elevated RANK-L/OPG ratio. However, this was not to be expected either as both markers only circulate in very small quantities and furthermore have half-lives sufficient to recirculate the vascular system many times, making it difficult to detect a local difference.

Regarding the increased level of AGEs after cooling, it is unclear whether this is an expression of a local increase in production of AGEs due to cooling, a by-product of the Charcot inflammation, or merely a random sampling variation. 
The presence of tissue-bound receptors for AGEs (RAGE) has been associated with impaired bone matrix mineralization and enhanced osteoclast formation [49]. AGEs have been linked to a negative modification of collagen integrity and fragile bones in general [50-52]. Thus, if there is indeed an increased level of AGEs present in Charcot feet, this might account for a further weakening of the bones. Furthermore, there is a link between increased levels of RAGE and activation of the NF- $\kappa$ B system and several associated cytokines $[53,54]$. As such, it shares a common pathway of influence of osteoclastic activation with RANK-L/OPG and by extension IL-6.

4.1. Strengths and Limitations. To our knowledge, this is the first time that the local venous-arterial flux across an acute Charcot foot has been studied. Furthermore, we are unaware of other studies that have limited the local A-V shunting effect prior to measuring a Charcot foot.

The study was limited by the number of available participants. In total, we screened 22 patients and most of these were excluded due to foot ulcers or extended time from the symptom onset to diagnosis. Thus, part of the recruitment issue was the rigorous exclusion criteria needed to ensure that any possible findings were not clouded by infections, surgery, or prolonged Charcot inflammation.

Furthermore, most of the assays we have used have a limited accuracy and substantial intraindividual variations, and thus it was difficult to register any possible differences. These variations might be the reason why we saw an increase in AGEs after cooling in the Charcot foot compared to the arterial level. Unless more accurate assays are developed, future tests in a similar setup could be performed with multiple samples from each site and each time point to help alleviate this issue.

\section{Conclusion}

In conclusion, we have found an increased venous-arterial flux of IL-6 in the acute diabetic Charcot foot compared to the healthy foot. We also found an increased level of IL-6 and AGEs in the acute Charcot foot compared to the arterial level after, but not before, externally cooling the feet.

\section{Data Availability}

All data, in anonymised form, are available upon contact to the corresponding author.

\section{Disclosure}

The foundations had no influence on the design, execution, results, or conclusions of the study.

\section{Conflicts of Interest}

The authors declare that they have no conflicts of interest.

\section{Acknowledgments}

This study was funded in part by donations from the private Danish foundations: "Toyota-Fonden" and "Brødrene Hartmanns Fond."

\section{Supplementary Materials}

Appendix 1 contains the primary output from the multiplex assay. The strength of the responses was used to evaluate the most likely markers for the final assay panel. (Supplementary Materials)

\section{References}

[1] A. Hartemann-Heurtier, G. H. van, and A. Grimaldi, "The Charcot foot," The Lancet, vol. 360, no. 9347, pp. 1776-1779, 2002.

[2] J. Fabrin, K. Larsen, and P. E. Holstein, "Long-term follow-up in diabetic Charcot feet with spontaneous onset," Diabetes Care, vol. 23, no. 6, pp. 796-800, 2000.

[3] L. Lee, P. A. Blume, and B. Sumpio, "Charcot joint disease in diabetes mellitus," Annals of Vascular Surgery, vol. 17, no. 5, pp. 571-580, 2003.

[4] L. C. Rogers and R. G. Frykberg, "The Charcot foot," The Medical Clinics of North America, vol. 97, no. 5, pp. 847-856, 2013.

[5] B. J. Grear, A. Rabinovich, and J. W. Brodsky, "Charcot arthropathy of the foot and ankle associated with rheumatoid arthritis," Foot \& Ankle International, vol. 34, no. 11, pp. 1541-1547, 2013.

[6] M. E. Munson, J. S. Wrobel, C. M. Holmes, and D. A. Hanauer, "Data mining for identifying novel associations and temporal relationships with Charcot foot," Journal of Diabetes Research, vol. 2014, Article ID 214353, 13 pages, 2014.

[7] J. T. Bariteau, S. Tenenbaum, A. Rabinovich, and J. W. Brodsky, "Charcot arthropathy of the foot and ankle in patients with idiopathic neuropathy," Foot \& Ankle International, vol. 35, no. 10, pp. 996-1001, 2014.

[8] N. L. Petrova and M. E. Edmonds, "Charcot neuroosteoarthropathy-current standards," Diabetes/Metabolism Research and Reviews, vol. 24, Supplement 1, pp. S58-S61, 2008.

[9] J. D. Ward, “The diabetic leg," Diabetologia, vol. 22, no. 3, pp. 141-147, 1982.

[10] L. C. Rogers, R. G. Frykberg, D. G. Armstrong et al., "The Charcot foot in diabetes," Journal of the American Podiatric Medical Association, vol. 101, no. 5, pp. 437-446, 2011.

[11] A. J. M. Boulton, "Diabetic neuropathy and foot complications," Handbook of Clinical Neurology, vol. 126, pp. 97-107, 2014.

[12] S. M. Rajbhandari, R. C. Jenkins, C. Davies, and S. Tesfaye, "Charcot neuroarthropathy in diabetes mellitus," Diabetologia, vol. 45, no. 8, pp. 1085-1096, 2002.

[13] W. J. Jeffcoate, F. Game, and P. R. Cavanagh, "The role of proinflammatory cytokines in the cause of neuropathic osteoarthropathy (acute Charcot foot) in diabetes," The Lancet, vol. 366, no. 9502, pp. 2058-2061, 2005.

[14] W. J. Jeffcoate, "Charcot neuro-osteoarthropathy," Diabetes/ Metabolism Research and Reviews, vol. 24, Supplement 1, pp. S62-S65, 2008. 
[15] G. Mabilleau and M. E. Edmonds, "Role of neuropathy on fracture healing in Charcot neuro-osteoarthropathy," Journal of Musculoskeletal \& Neuronal Interactions, vol. 10, no. 1, pp. 84-91, 2010.

[16] E. Chantelau and G. J. Onvlee, "Charcot foot in diabetes: farewell to the neurotrophic theory," Hormone and Metabolic Research, vol. 38, no. 6, pp. 361-367, 2006.

[17] N. L. Petrova, T. K. Dew, R. L. Musto et al., "Inflammatory and bone turnover markers in a cross-sectional and prospective study of acute Charcot osteoarthropathy," Diabetic Medicine, vol. 32, no. 2, pp. 267-273, 2015.

[18] L. Uccioli, A. Sinistro, C. Almerighi et al., "Proinflammatory modulation of the surface and cytokine phenotype of monocytes in patients with acute Charcot foot," Diabetes Care, vol. 33, no. 2, pp. 350-355, 2010.

[19] A. Piaggesi, L. Rizzo, F. Golia et al., "Biochemical and ultrasound tests for early diagnosis of active neuro-osteoarthropathy (NOA) of the diabetic foot," Diabetes Research and Clinical Practice, vol. 58, no. 1, pp. 1-9, 2002.

[20] G. Mabilleau, N. L. Petrova, M. E. Edmonds, and A. Sabokbar, "Increased osteoclastic activity in acute Charcot's osteoarthopathy: the role of receptor activator of nuclear factor-kappaB ligand," Diabetologia, vol. 51, no. 6, pp. 1035-1040, 2008.

[21] A. Gough, H. Abraha, F. Li et al., "Measurement of markers of osteoclast and osteoblast activity in patients with acute and chronic diabetic Charcot neuroarthropathy," Diabetic Medicine, vol. 14, no. 7, pp. 527-531, 1997.

[22] A. Ndip, A. Williams, E. B. Jude et al., "The RANKL/RANK/ OPG signaling pathway mediates medial arterial calcification in diabetic Charcot neuroarthropathy," Diabetes, vol. 60, no. 8, pp. 2187-2196, 2011.

[23] R. G. Pearson, K. S. Shu, H. Divyateja et al., "Charcot neuropathic osteoarthropathy, pro-inflammatory cytokines and bone turnover markers," Orthopaedic Proceedings, vol. 94-B, Supplement XXXVI, p. 101, 2012.

[24] H. Divyateja, K. S. S. Shu, R. G. Pearson, B. E. Scammell, F. L. Game, and W. J. Jeffcoate, "Local and systemic concentration of pro-inflammatory cytokines, osteoprotegerin, sRANKL and bone turnover markers in acute Charcot foot and in controls," Diabetologia, vol. 54, Supplement 1, pp. S11-S12, 2011.

[25] N. L. Petrova, P. K. Petrov, M. E. Edmonds, and C. M. Shanahan, "Novel use of a Dektak 150 surface profiler unmasks differences in resorption pit profiles between control and Charcot patient osteoclasts," Calcified Tissue International, vol. 94, no. 4, pp. 403-411, 2014.

[26] J. La Fontaine, N. Shibuya, H. W. Sampson, and P. Valderrama, "Trabecular quality and cellular characteristics of normal, diabetic, and Charcot bone," The Journal of Foot \& Ankle Surgery, vol. 50, no. 6, pp. 648-653, 2011.

[27] A. Folestad, M. Ålund, S. Asteberg et al., "IL-17 cytokines in bone healing of diabetic Charcot arthropathy patients: a prospective 2 year follow-up study," Journal of Foot and Ankle Research, vol. 8, no. 1, p. 39, 2015.

[28] A. Folestad, M. Ålund, S. Asteberg et al., "Role of Wnt/ $\beta$ catenin and RANKL/OPG in bone healing of diabetic Charcot arthropathy patients," Acta Orthopaedica, vol. 86, no. 4, pp. 415-425, 2015.

[29] A. Folestad, M. Ålund, S. Asteberg et al., "Offloading treatment is linked to activation of proinflammatory cytokines and start of bone repair and remodeling in Charcot arthropathy patients," Journal of Foot and Ankle Research, vol. 8, no. 1, p. 72, 2015.

[30] S. Sinha, C. S. Munichoodappa, and G. P. Kozak, "Neuroarthropathy (Charcot joints) in diabetes mellitus (clinical study of 101 cases)," Medicine, vol. 51, no. 3, pp. 191-210, 1972.

[31] D. G. Armstrong, W. F. Todd, L. A. Lavery, L. B. Harkless, and T. R. Bushman, "The natural history of acute Charcot's arthropathy in a diabetic foot specialty clinic," Diabetic Medicine, vol. 14, no. 5, pp. 357-363, 1997.

[32] N. L. Petrova and C. M. Shanahan, "Neuropathy and the vascular-bone axis in diabetes: lessons from Charcot osteoarthropathy," Osteoporosis International, vol. 25, no. 4, pp. 1197-1207, 2014.

[33] A. M. Sattler, M. Schoppet, J. R. Schaefer, and L. C. Hofbauer, "Novel aspects on RANK ligand and osteoprotegerin in osteoporosis and vascular disease," Calcified Tissue International, vol. 74, no. 1, pp. 103-106, 2004.

[34] L. C. Hofbauer and M. Schoppet, "Clinical implications of the osteoprotegerin/RANKL/RANK system for bone and vascular diseases," JAMA, vol. 292, no. 4, pp. 490-495, 2004.

[35] K. A. Witzke, A. I. Vinik, L. M. Grant et al., "Loss of RAGE defense: a cause of Charcot neuroarthropathy?," Diabetes Care, vol. 34, no. 7, pp. 1617-1621, 2011.

[36] T. M. Christensen, L. Simonsen, P. E. Holstein, O. L. Svendsen, and J. Bülow, "Sympathetic neuropathy in diabetes mellitus patients does not elicit Charcot osteoarthropathy," Journal of Diabetes and its Complications, vol. 25, no. 5, pp. 320-324, 2011.

[37] M. Guillot, G. Vanneuville, G. Escande, J. Chazal, and A. Tanguy, "Anatomical study and systematization of veins in the foot," Bulletin de l'Association des anatomistes, vol. 63, no. 183, pp. 425-433, 1979.

[38] J. J. Bergan and N. Bunke, The Vein Book, Oxford University Press, 2013.

[39] G. Kuster, E. P. Lofgren, and W. H. Hollinshead, “Anatomy of the veins of the foot," Surgery, Gynecology \& Obstetrics, vol. 127, no. 4, pp. 817-823, 1968.

[40] L. Walløe, "Arterio-venous anastomoses in the human skin and their role in temperature control," Temperature, vol. 3, no. 1, pp. 92-103, 2016.

[41] R. B. Jansen, T. M. Christensen, J. Bülow et al., "Bone mineral density and markers of bone turnover and inflammation in diabetes patients with or without a Charcot foot: an 8.5-year prospective case-control study," Journal of Diabetes and its Complications, vol. 32, no. 2, pp. 164-170, 2018.

[42] S. C. Manolagas, "Role of cytokines in bone resorption," Bone, vol. 17, no. 2, pp. S63-S67, 1995.

[43] R. Nishimura, K. Moriyama, K. Yasukawa, G. R. Mundy, and T. Yoneda, "Combination of interleukin-6 and soluble interleukin- 6 receptors induces differentiation and activation of JAK-STAT and MAP kinase pathways in MG-63 human osteoblastic cells," Journal of Bone and Mineral Research, vol. 13, no. 5, pp. 777-785, 1998.

[44] K. Yokota, K. Sato, T. Miyazaki et al., "Combination of tumor necrosis factor $\alpha$ and interleukin- 6 induces mouse osteoclastlike cells with bone resorption activity both in vitro and in vivo," Arthritis \& Rheumatology, vol. 66, no. 1, pp. 121129,2014

[45] C. A. O’Brien, I. Gubrij, S.-C. Lin, R. L. Saylors, and S. C. Manolagas, "STAT3 activation in stromal/osteoblastic cells 
is required for induction of the receptor activator of NF- $\kappa \mathrm{B}$ ligand and stimulation of osteoclastogenesis by gp130utilizing cytokines or interleukin-1 but not 1,25-dihydroxyvitamin D3or parathyroid hormone," Journal of Biological Chemistry, vol. 274, no. 27, pp. 19301-19308, 1999.

[46] J. F. Baumhauer, R. J. O'Keefe, L. C. Schon, and M. S. Pinzur, "Cytokine-induced osteoclastic bone resorption in Charcot arthropathy: an immunohistochemical study," Foot \& Ankle International, vol. 27, no. 10, pp. 797-800, 2006.

[47] N. L. Petrova, P. K. Petrov, M. E. Edmonds, and C. M. Shanahan, "Inhibition of TNF- $\alpha$ reverses the pathological resorption pit profile of osteoclasts from patients with acute Charcot osteoarthropathy," Journal of Diabetes Research, vol. 2015, Article ID 917945, 10 pages, 2015.

[48] M. Nybo, M. K. Poulsen, J. Grauslund, J. E. Henriksen, and L. M. Rasmussen, "Plasma osteoprotegerin concentrations in peripheral sensory neuropathy in type 1 and type 2 diabetic patients," Diabetic Medicine, vol. 27, no. 3, pp. 289-294, 2010.

[49] S. Yaturu, "Diabetes and skeletal health," Journal of Diabetes, vol. 1, no. 4, pp. 246-254, 2009.

[50] N. C. Chilelli, S. Burlina, and A. Lapolla, “AGEs, rather than hyperglycemia, are responsible for microvascular complications in diabetes: a "glycoxidation-centric" point of view," Nutrition, Metabolism and Cardiovascular Diseases, vol. 23, no. 10, pp. 913-919, 2013.

[51] R. G. Paul and A. J. Bailey, "Glycation of collagen: the basis of its central role in the late complications of ageing and diabetes," The International Journal of Biochemistry \& Cell Biology, vol. 28, no. 12, pp. 1297-1310, 1996.

[52] A. A. Poundarik, P.-C. Wu, Z. Evis et al., "A direct role of collagen glycation in bone fracture," Journal of the Mechanical Behavior of Biomedical Materials, vol. 52, pp. 120-130, 2015.

[53] A. Bierhaus, S. Schiekofer, M. Schwaninger et al., "Diabetesassociated sustained activation of the transcription factor nuclear factor- $\kappa \mathrm{B}$," Diabetes, vol. 50, no. 12, pp. 2792-2808, 2001.

[54] K.-M. Haslbeck, E. Schleicher, A. Bierhaus et al., "The AGE/ RAGE/NF- $\kappa$ B pathway may contribute to the pathogenesis of polyneuropathy in impaired glucose tolerance (IGT)," Experimental and Clinical Endocrinology \& Diabetes, vol. 113, no. 5, pp. 288-291, 2005. 


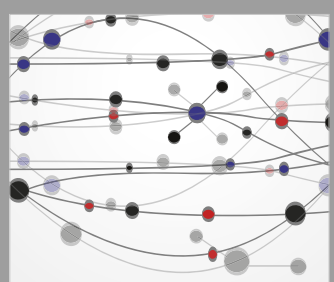

The Scientific World Journal
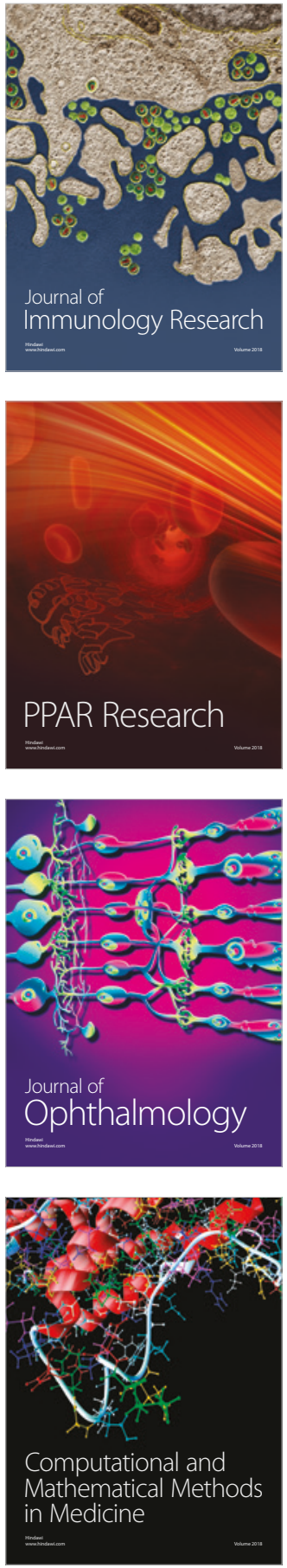

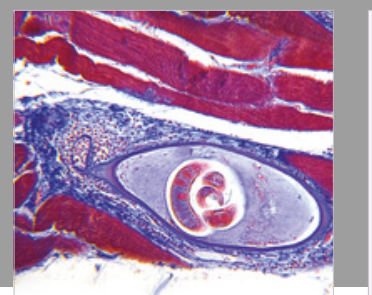

Gastroenterology Research and Practice

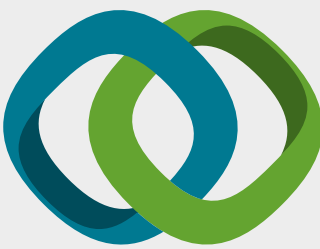

\section{Hindawi}

Submit your manuscripts at

www.hindawi.com
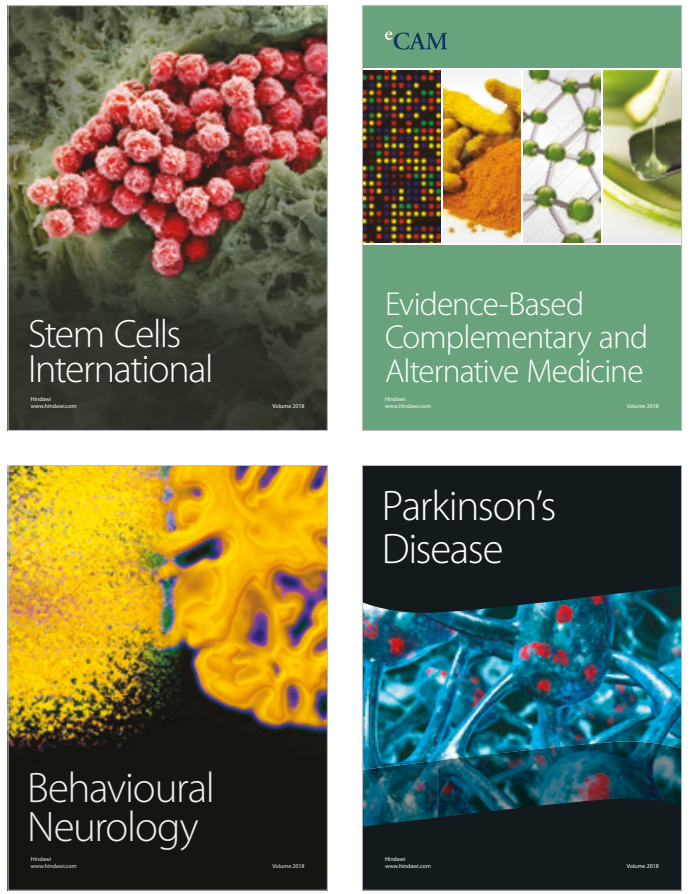

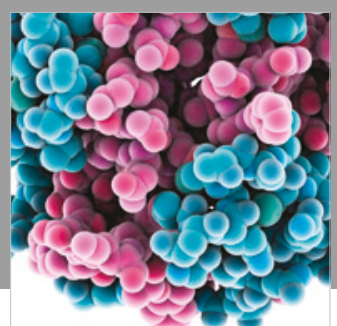

ournal of

Diabetes Research

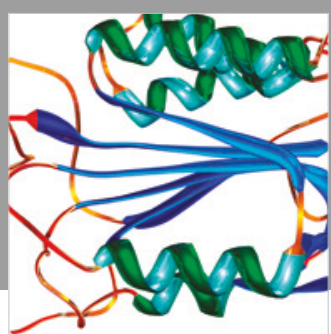

Disease Markers
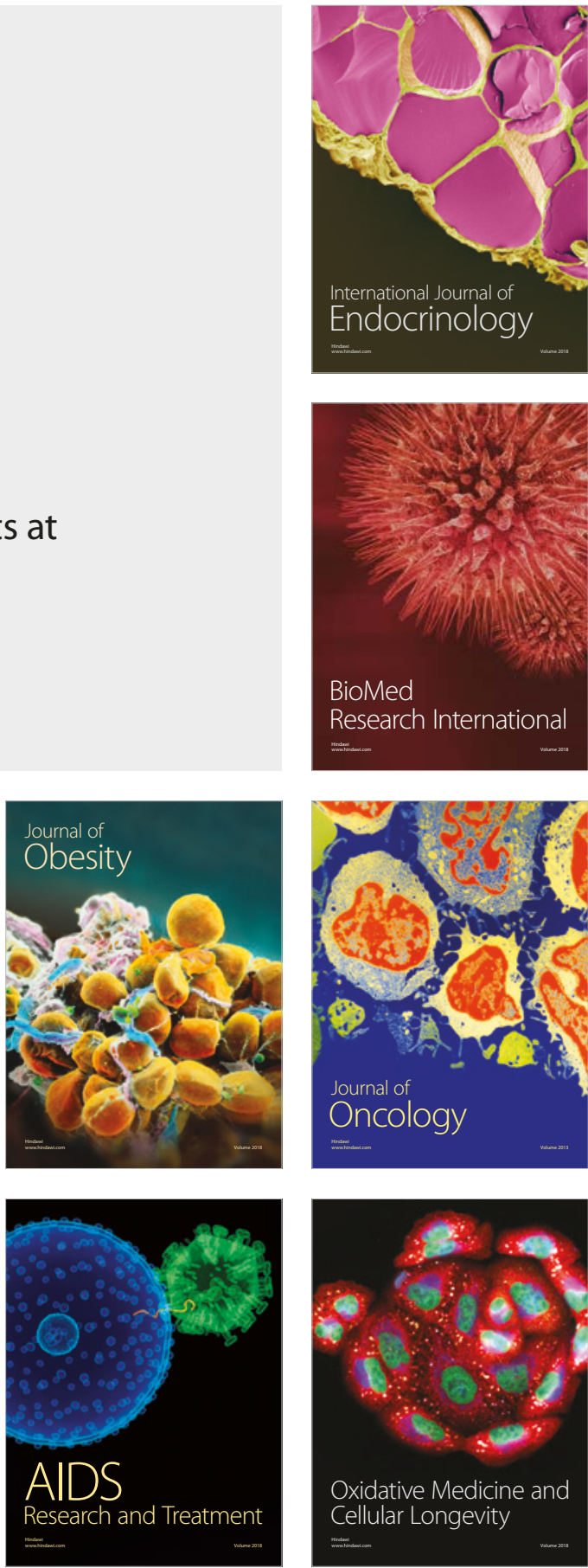